\title{
Evaluation of Motorcycle Energy Consumption in Urban Traffic
}

\author{
Stepan Pance ${ }^{1}$, Daniel Piskac ${ }^{1}$, Adam Bures ${ }^{1}$, Antonin Voldrich ${ }^{1}$, Maros Kovac ${ }^{1}$, Bentang Arief Budiman ${ }^{2,3^{*}}$ \\ ${ }^{1}$ Graduate student, Czech Technical University, Czech Republic \\ ${ }^{2}$ Faculty of Mechanical and Aerospace Engineering, Institut Teknologi Bandung, Indonesia \\ ${ }^{3}$ National Center for Sustainable Transportation Technology, Indonesia \\ *Email: bentang@ftmd.itb.ac.id
}

\begin{abstract}
This paper aims to evaluate the energy consumption of motorcycle operating in urban traffic. Position, speed, and elevation in each time segment are collected by GPS - tracking data from the journey of motorcycle Honda Verza 150 in Bandung city. The distance, acceleration, and required tractive force for the motorcycle motion are then calculated. Furthermore, the energy consumption is investigated by modeling the motorcycle and calculating tractive force from the force equilibrium. For each time segment, engaged gear is then proposed for the best energy efficiency. The relationship among speed, required tractive force, and shifted gear according to time and distance are comprehensively discussed.
\end{abstract}

\section{Keywords}

Motorcycle; Tractive force; Energy consumption; Gear ratio

\section{Introduction}

In Indonesia, the number of motorcycles is increased significantly in the last ten years. Figure 1 shows the growth of motorcycle compare to other road vehicles [1]. This growth is aggravated by limited and unreliable public transportation, especially in big cities such as Jakarta, Bandung, and Surabaya [2]. The motorcycle is also considerably cheap, has a low maintenance cost, and low taxes [3]. Furthermore, motorcycle sellers usually provide a secure payment scheme with little interest to attract low economic class customers.

The high number of motorcycles on the road might not be beneficial since those consume a lot of fossil fuel energy, which is mostly subsidized by the government [4]. Thus, the government must allocate a high budget for this subsidy. Too many motorcycles on the road can also increase heavy traffic jam and raise accident probability, especially when drivers do not follow traffic regulation [5].

In order to reduce energy consumption and improve safety during driving motorcycle, effective driving behavior can be implemented [6]. One of the practices is to select proper gear, which might generate the most efficient fuel consumption [7]. Calculation of energy and power consumption in a vehicle needs to be done accurately. Thus, gear selection and shifting can be appropriately determined. The calculation is influenced by various parameters, including road condition [8], traffic jam [9], and environment.

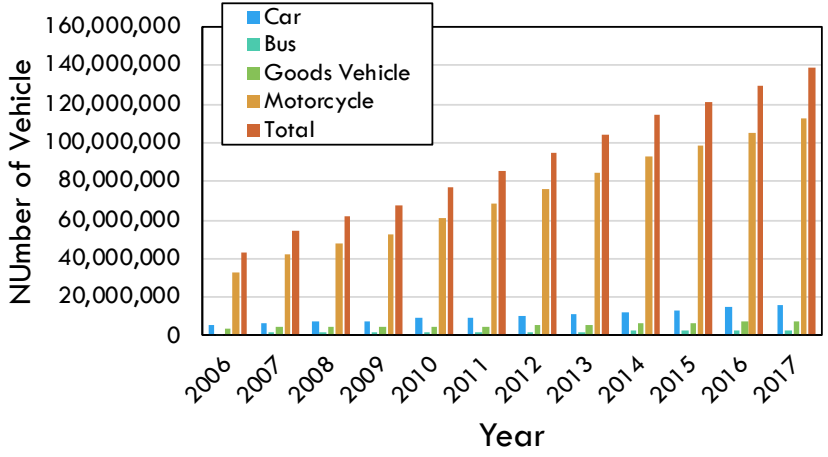

Figure 1 Number of vehicles in Indonesia

In this paper, an evaluation of energy consumption on a motorcycle running in urban traffic was demonstrated. Various parameters which affect energy consumption were considered in detail. From the calculation, the ideal selected gear which can minimize energy consumption at each waypoint is presented. Furthermore, some driving strategies which might improve energy efficiency are also comprehensively discussed.

\section{Data Collection}

The motorcycle used for this test was Honda Verza 150, manufactured in the year of 2013. OsmAnd program, an Android-based software, was used to collect the necessary data from Global Positioning System (GPS). The track test from parking the lot at ITB campus dormitory to Dago Pojok street was selected for this test (see Figure 2). 
The GPS data provides vehicle position, vehicle speed $(v)$, and road elevation $(e)$. Data points were collected in intervals of 2-4 seconds. The total distance was 2,85 $\mathrm{km}$, and it took the time of 3 minutes and 56 seconds for the driver to finish the track. Compare to the speedometer in motorcycle dashboard; it is found that the accuracy of GPS data at low speed is not too accurate. However, as motorcycle speed increasing, the error becomes smaller. Figure 3 shows $v$ and $e$ curves obtained from GPS. It can be seen from the $e$ curve that Dago Pojok street is placed at higher land than ITB campus. Since the testing was conducted at night, there is relatively no traffic jam. Thus, the average speed of $44 \mathrm{~km} / \mathrm{h}$ can be achieved.

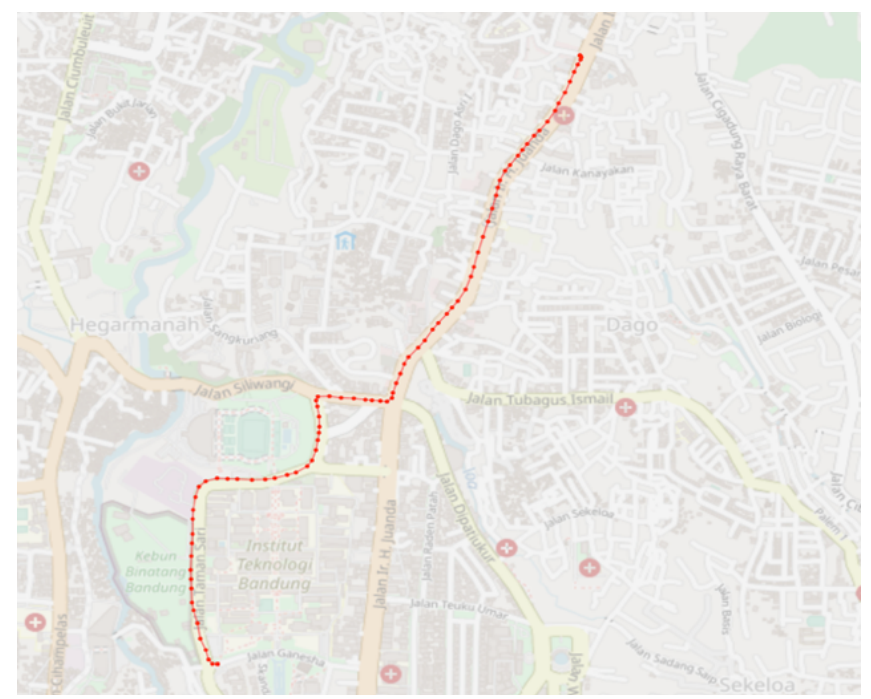

Figure 2 Track for testing

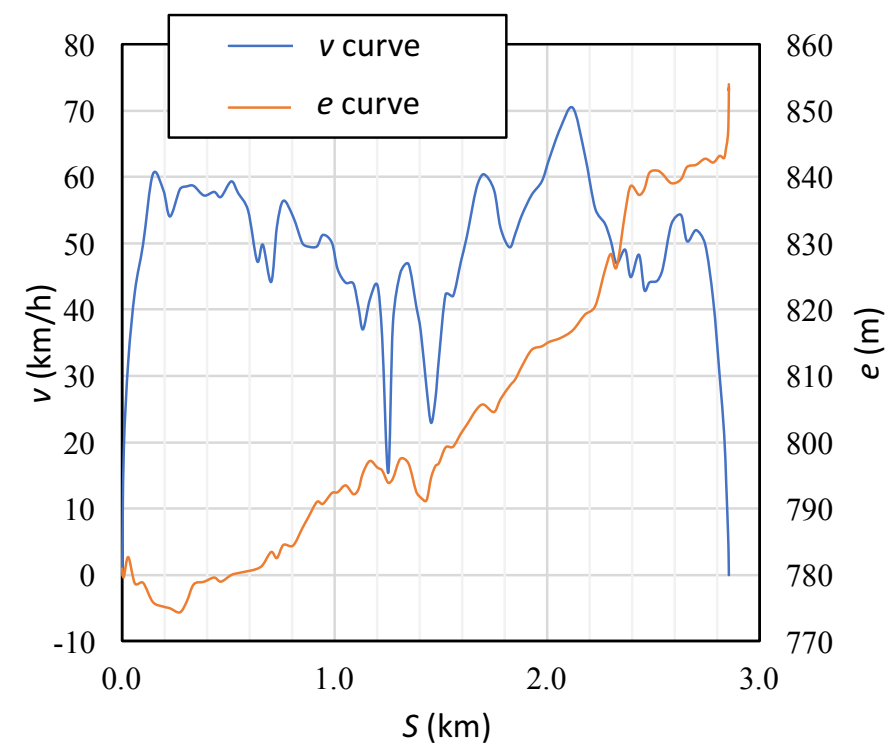

Figure 3 Velocity and elevation obtained from GPS data tracking

\section{Mathematical Formulation}

From the speed data obtained by GPS, moving distance $(S)$ can be calculated by integrating the $v$ data to time $(t)$. Furthermore, the acceleration $(a)$ can also be obtained by deriving the $v$ data to $t$. Those parameters are stated in (1) and (2), respectively.

$$
\begin{aligned}
& S=\int v d t \\
& a=\frac{d v}{d t}
\end{aligned}
$$

From the force equilibrium of the motorcycle, the tractive force $\left(F_{t}\right)$ required by the vehicle to move with $a$ can be calculated as follows [10],

$$
F_{t}-R_{g}-R_{a}-R_{r}=m a
$$

Where $R_{g}$ is grade resistance, $R_{a}$ is aerodynamic resistance, $R_{r}$ is rolling resistance, and $m$ is the total mass of motorcycle and driver.

The $R_{g}$ can be then calculated as follows,

$$
R_{g}=m g \sin \theta
$$

Where $g$ is gravitational acceleration and $\theta$ is an elevated angle. For small $\theta$,

$$
\sin \theta \approx \tan \theta=\frac{d e}{d S}
$$

Furthermore, $R_{a}$ can be calculated as follows,

$$
R_{a}=\frac{\rho}{2} c_{d} A_{f} v^{2}
$$

Where $\rho$ is the density of air, $c_{d}$ is aerodynamic resistance coefficient of drag and driver, and $A_{f}$ is the frontal area of the motorcycle.

The $R_{r}$ can be calculated as follows,

$$
R_{r}=f_{r} m
$$


Where $f_{r}$ is rolling resistance coefficient which depends on tire deformation when contacting the road.

From $F_{t}$ data, the power required to move the motorcycle $(P)$ can be calculated as follows,

$$
P=F_{\mathrm{t}} v
$$

The total energy $(E)$ can be calculated as follows,

$$
E=\int P d t
$$

To obtain efficient required energy for driving a motorcycle, Internal Combustion Engine (ICE) of the motorcycle must be in an optimum point in which the ICE can provide maximum torque $\left(T_{\text {engine }}^{\max }\right)$ with minimum fuel consumption. From the datasheet, $T_{\max }$ of 12.7 $\mathrm{Nm}$ and $\omega$ of $6500 \mathrm{rpm}$ are most efficient for the ICE. Thus, the gear number is selected by considering this condition.

The maximum torsion transferred to the wheel can be calculated as follows,

$$
T_{\text {wheel }}^{\max }=T_{\text {engine }}^{\max } g_{r t}
$$

Where $g_{r t}$ is total gear ratio. Furthermore, $F_{t}$ can be obtained by using equation as follows,

$$
F_{t}=T_{w h e e l}^{\max } r_{w}
$$

Where $r_{w}$ is wheel diameter.

Consider 20\% losses in drivetrain, transmission, and wheels, the actual tractive force produced by drivetrain can be calculated as follows,

$$
F_{t}^{\text {actual }}=0.8 F_{t}
$$

\section{Results and Discussion}

Table 1 shows the required parameters for calculation of force equilibrium and energy consumption. Figure 4 shows the curves of $R_{g}, R_{a}$, and $R_{r}$ for each time segment. It can be seen that grade resistance give a significant influence on the vehicle movement, followed by aerodynamic and rolling resistance. This result is expected since the test track has elevated condition.

From (3), the tractive force can be obtained. Figure 5 shows the curve of the tractive force. There is a negative tractive force which is caused by the braking condition. From the tractive force, the power required to move the vehicle can also be calculated. Figure 6 shows the power curve. By integrating the power curve to time, the total energy consumption can be obtained and plotted in Figure 6 too. Negative power is not considered here because it is caused by mechanical braking, not regenerative braking in which the energy can be absorbed. The total energy required to complete the ride is $131.8 \mathrm{Wh}$.

Table 1 Parameters for calculation

\begin{tabular}{cc}
\hline Parameter & Value \\
\hline$m$ & $220 \mathrm{~kg}$ \\
$\rho$ & $1.225 \mathrm{~kg} / \mathrm{m}^{3}$ \\
$A_{f}$ & $0.8 \mathrm{~m}^{2}$ \\
$C_{d}$ & 0.5 \\
$f_{r}$ & 0.02 \\
$g$ & $9.8 \mathrm{~m} / \mathrm{s}^{2}$ \\
$T_{\max }$ & $12.7 \mathrm{Nm}$ \\
$\omega$ & $6500 \mathrm{rpm}$ \\
\hline
\end{tabular}

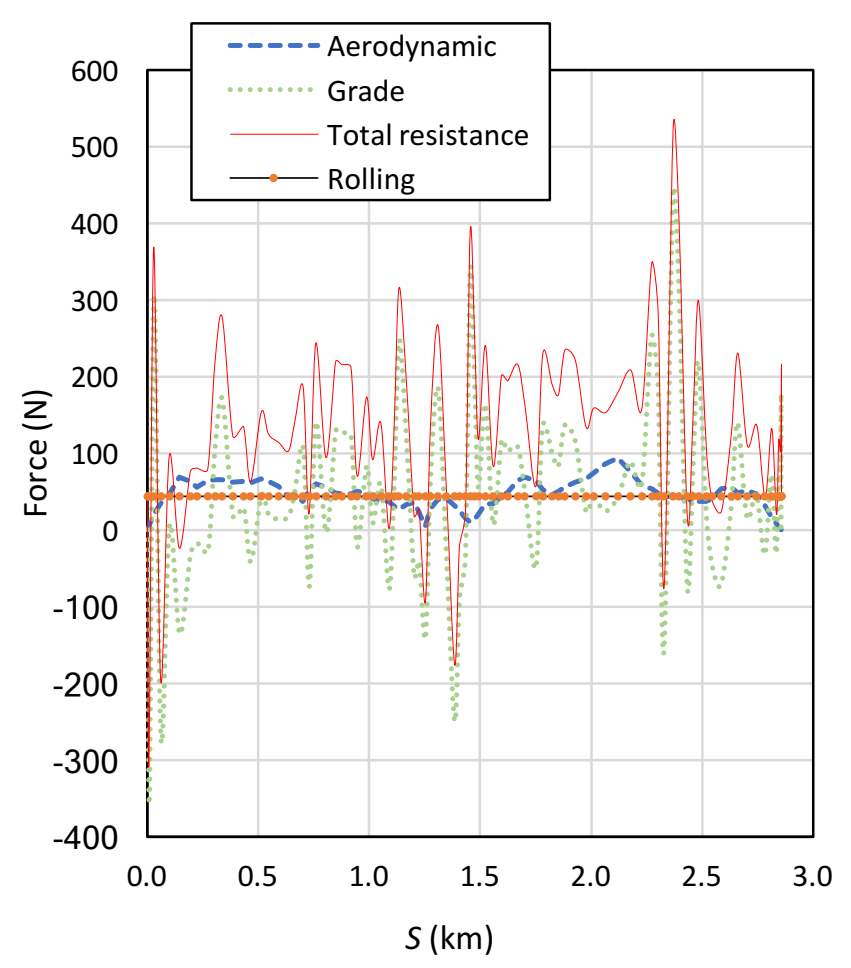

Figure $4 R_{g}, R_{a}$, and $R_{r}$ curves calculated by using (4), (6), and (7), respectively 


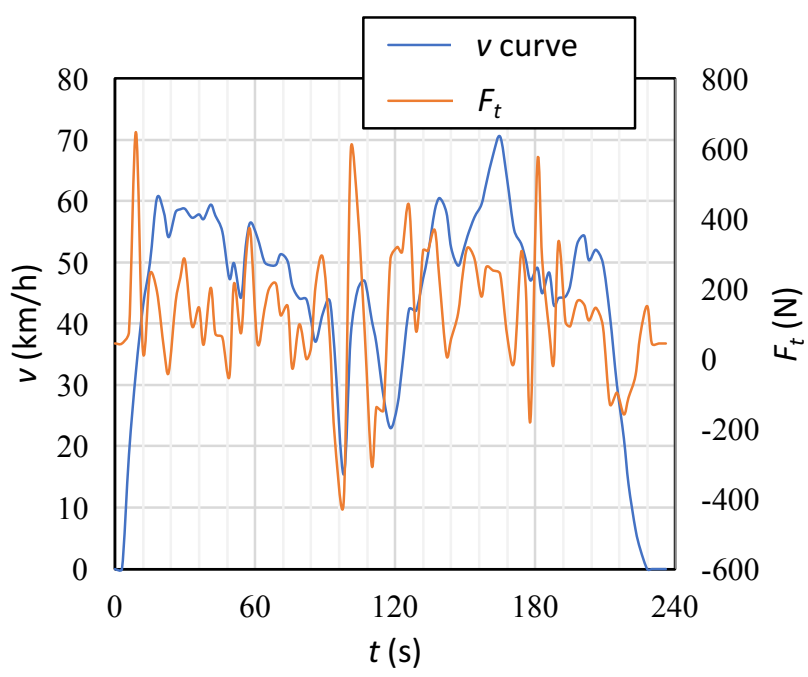

Figure 5 Speed and tractive force in motorcycle

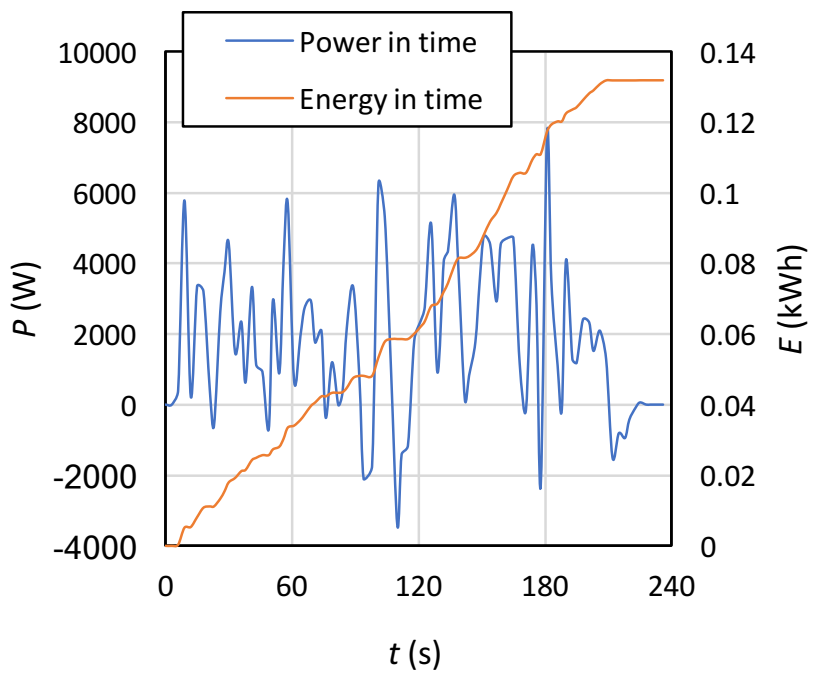

Figure 6 Power and energy consumption in motorcycle

After $v$ and required $F_{t}$ at any measured waypoint are obtained, the ideal gear is then selected. A multiple "IF" function which selects the highest possible gear is created according to "Shift UP" values in Table 2. After the gear is selected, the function checks if the required $F_{t}$ is lower than $F_{t}^{\text {actual }}$ (see Table 3). If the required $F_{t}$ is higher, the gear is shifted to lower one until the required $F_{t}$ is lower than the $F_{t}^{a c t u a l}$. The gear shifting can only be repeated once in maximum for gears 3 and 2 in, and twice for gears 5 and 4 . This approach can ensure that any exceedingly low gear is selected in case of any significant inaccuracy in measured data using GPS. Figure 7 shows ideal gear that should be selected by the driver to obtain minimum energy and fuel consumption. It can be seen that the tendency of the selected gear curve is mostly similar to $v$ of the motorcycle.
Table 2 Parameter of gear

\begin{tabular}{cccccc}
\hline Gear & $\begin{array}{c}\text { Total } \\
\text { gear } \\
\text { ratio }-g_{\text {rt }}\end{array}$ & $\begin{array}{c}\text { Speed } \\
\text { at Idle } \\
(\mathbf{k m} / \mathbf{h})\end{array}$ & $\begin{array}{c}\text { Speed at } \\
\text { Redline } \\
\mathbf{( k m / h )}\end{array}$ & $\begin{array}{c}\text { Shift } \\
\mathbf{D O W N} \\
\mathbf{( k m} / \mathbf{h})\end{array}$ & $\begin{array}{c}\text { Shift } \\
\mathbf{U P} \\
\mathbf{( k m / h )}\end{array}$ \\
\hline 1 & 27.05 & 6.4 & 40.32 & - & 21.12 \\
2 & 17.01 & 10.08 & 63.68 & 20.16 & 33.6 \\
3 & 12.95 & 13.28 & 84.16 & 26.56 & 44.32 \\
4 & 10.47 & 16.48 & 104.16 & 32.8 & 54.72 \\
5 & 9.13 & 18.88 & 119.36 & 37.76 & - \\
\hline
\end{tabular}

Table 3 Torque and forces for each gear

\begin{tabular}{cccc}
\hline Gear & $T_{\text {wheel }}^{\text {max }}(\mathbf{N m})$ & $F_{t}^{\max } \mathbf{( N m )}$ & $F_{t}^{\text {actual }}(\mathbf{N m})$ \\
\hline 1 & 343.5 & 1116.8 & 893.4 \\
2 & 217.1 & 705.8 & 564.6 \\
3 & 164.5 & 534.7 & 427.8 \\
4 & 132.9 & 432.0 & 345.6 \\
5 & 115.9 & 376.8 & 301.4 \\
\hline
\end{tabular}

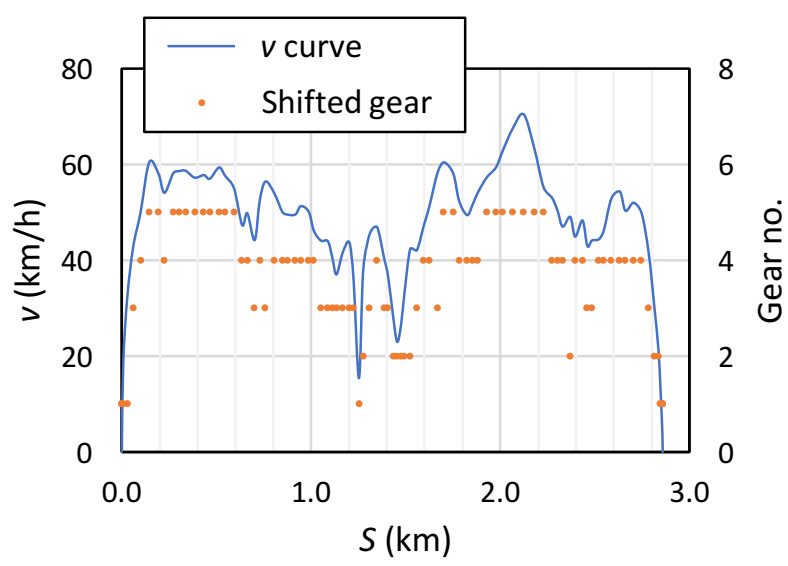

Figure 7 Ideal gear recommendation

\section{Conclusion}

The goal in this work is to determine the relationship between tractive force on driving conditions and speed, according to the selected ideal/efficient gear. Position, speed, and elevation were obtained by using free software app OsmAnd. The result meets the expectation. However, this simple setup can lead to some uncertainties, especially in elevation changes for low speeds, which can significantly influence the final result by changing the slope of the road to unrealistic values. The energy consumption is then obtained from the tractive force, which calculated by using the force equilibrium of the motorcycle. The most important results are represented in Figure 7, which presents the relationship between speed and ideal shifted gear according to time and distance, respectively. 


\section{Acknowledgment}

This paper is supported by USAID through Sustainable Higher Education Research Alliances (SHERA) program with grant number IIE00000078-ITB-1.

\section{References}

[1] Badan Pusat Statistik, "Perkembangan Jumlah Kendaraan Bermotor Menurut Jenis, 1949-2017.” [Online]. Available: https://www.bps.go.id/dynamictable/2016/02/09/1133/per kembangan-jumlah-kendaraan-bermotor-menurut-jenis1949-2017.html. [Accessed: 27-Aug-2018].

[2] M. Farda and H. Lubis, "Transportation System Development and Challenge in Jakarta Metropolitan Area, Indonesia," Int. J. Sustain. Transp. Technol., vol. 1, no. 2, pp. $42-50$, Oct. 2018

[3] R. Suryo, C. Fan, and S. Weiler, "Commuting choices and congestion taxes in industrializing Indonesia," Soc. Sci. J., vol. 44, no. 2, pp. 253-273, Jan. 2007.

[4] T. Dartanto, "Reducing fuel subsidies and the implication on fiscal balance and poverty in Indonesia: A simulation analysis," Energy Policy, vol. 58, pp. 117-134, Jul. 2013.

[5] A. Jusuf, I. P. Nurprasetio, and A. Prihutama, "Macro Data Analysis of Traffic Accidents in Indonesia," J. Eng. Technol. Sci., vol. 49, no. 1, pp. 132-143, Apr. 2017.

[6] T. A. Ranney, "Models of driving behavior: A review of their evolution," Accid. Anal. Prev., vol. 26, no. 6, pp. 733750, Dec. 1994.

[7] C. M. Kichler, J. P. Fulton, R. L. Raper, T. P. McDonald, and W. C. Zech, "Effects of transmission gear selection on tractor performance and fuel costs during deep tillage operations," Soil Tillage Res., vol. 113, no. 2, pp. 105-111, Jun. 2011.

[8] I. P. Nurprasetio, B. A. Budiman, K. Noersalim, and R. S. Naufal, "Pengembangan Metode Rekonstruksi Jalan Berbasis Data Global Positioning System dan Giroskop," MESIN, vol. 26, no. 1, pp. 17-28, Apr. 2017.

[9] S. K. Endarnoto, S. Pradipta, A. S. Nugroho, and J. Purnama, "Traffic Condition Information Extraction \& Visualization from Social Media Twitter for Android Mobile Application," in Proceedings of the 2011 International Conference on Electrical Engineering and Informatics, 2011, pp. 1-4.

[10] J. Y. Wong, Theory of ground vehicles. Wiley, 2008. 